\title{
The Effects of Plasma Homocysteine in PCOS Women: A Review
}

\author{
Pranita Maharjan, Peng Dan Hong* \\ Department of Obstetrics and Gynecology, Zhongda Hospital, Southeast University, Nanjing, China \\ Email: *pranimrj@gmail.com
}

How to cite this paper: Maharjan, P. and Hong, P.D. (2018) The Effects of Plasma Homocysteine in PCOS Women: A Review. Open Journal of Obstetrics and Gynecolo$g y, 8,39-50$.

https://doi.org/10.4236/ojog.2018.81005

Received: December 10, 2017

Accepted: January 12, 2018

Published: January 15, 2018

Copyright (๑) 2018 by authors and Scientific Research Publishing Inc. This work is licensed under the Creative Commons Attribution International License (CC BY 4.0).

http://creativecommons.org/licenses/by/4.0/

(c) (i) Open Access

\begin{abstract}
Homocysteine is an intermediate substance formed during the breakdown of the amino acid methionine and may undergo remethylation to methionine or trans-sulfuration to cystathionine or cysteine. The metabolism occurs via two pathways: remethylation to methionine, which requires folate and vitamin B12; and transsulfuration to cystathionine, which requires pyridoxal-5'-phosphate. The disturbances in the metabolic pathways lead to the accumulation of Hcy, either by insufficient transsulfuration (through CBS mutations or vitamin B6 deficiency) or by a blockage of remethylation. In the latter case, folate or vitamin B12 deficiency may be involved, as well as MTHFR. High levels of Hcy induce sustained injury of arterial endothelial cells, proliferation of arterial smooth muscle cells and enhance activity of key participants in vascular inflammation, atherogenesis, and vulnerability of the established atherosclerotic plaque. Hyperhomocysteinemia has become the topic of interest in recent years. It has been highly associated with increased risk for cardiovascular disorders, such as, atherosclerosis, thromboembolism and dyslipidemia. Women with PCOS show constellation of metabolic syndromes. Obesity, hyperandrogenemia and type 2 diabetes mellitus is the hallmark of PCOS which later becomes the risk factors for cardiovascular disease. Various studies had revealed the presence of increased Hcy level in PCOS women which may or may not be associated with other biochemical parameters. Intense treatment for PCOS can influence homocysteine levels.
\end{abstract}

\section{Keywords}

Polycystic Ovary Syndrome, Homocysteine, Insulin Resistance

\section{Introduction}

Polycystic ovary syndrome (PCOS) proves as the most common endocrine dis- 
order with a prevalence of $5 \%$ to $15 \%$ worldwide [1], for the women of active reproductive age, but the prevalent rate varies depending on the criteria used for the diagnosis [2] [3]. According to the Rotterdam diagnostic criteria, the prevalence rate of PCOS accounts up to $18 \%$ of reproductive-aged women [2] [3], whilst the prevalence rate is $10 \%$ when using NIH criteria for diagnosis criteria [3] but the prevalence is still unknown in children [2] [4]. Three different criteria have been implemented for the diagnosis of PCOS: the NIH criteria (1990), the Rotterdam criteria (2003) and the Androgen and PCOS society (AE-PCOS) criteria (2006) [5] [6]. Amongst the three criteria, the Rotterdam criterion was adopted as the Practice Guidelines of the Endocrine Society [2] [7]. The Rotterdam criteria comprise features as, chronic menstrual dysfunction, clinical or biochemical hyperandrogenism and polycystic ovaries confirmed by ultrasonography ( $\geq 10$ follicles and $\geq 10 \mathrm{ml}$ ovarian volume) [8]. The etiology of PCOS still remains unclear but various predisposing genes interfere with environmental and lifestyle manners [5] [9], makes PCOS a complex genetic disorder. The constellations of symptoms significantly affect the quality of life of PCOS women and the syndrome is associated with an increased long term risk factors such as cardiovascular disease, diabetes mellitus, infertility, cancer and psychological disorders [10].

In current years, homocysteine, a biosynthesis of methionine has proved as a major cardinal feature of PCOS. It is a non-protein a-amino acid and cysteine homologue. Its metabolic pathway encompasses either remethylation to methionine or through transsulfuration to cystathionine as shown in Figure 1 [11]. The first metabolism pathway requires folate and vitamin B12 whereas the latter requires pyridoxal-5'-phosphate. S-adenosylmethionine (SAM) augments the synthesis of both pathways which is a moderator of methylenetetrahydrofolate reductase (MTHFR) and inhibitor of cystathionine $\beta$-synthase (CBS). The metabolic

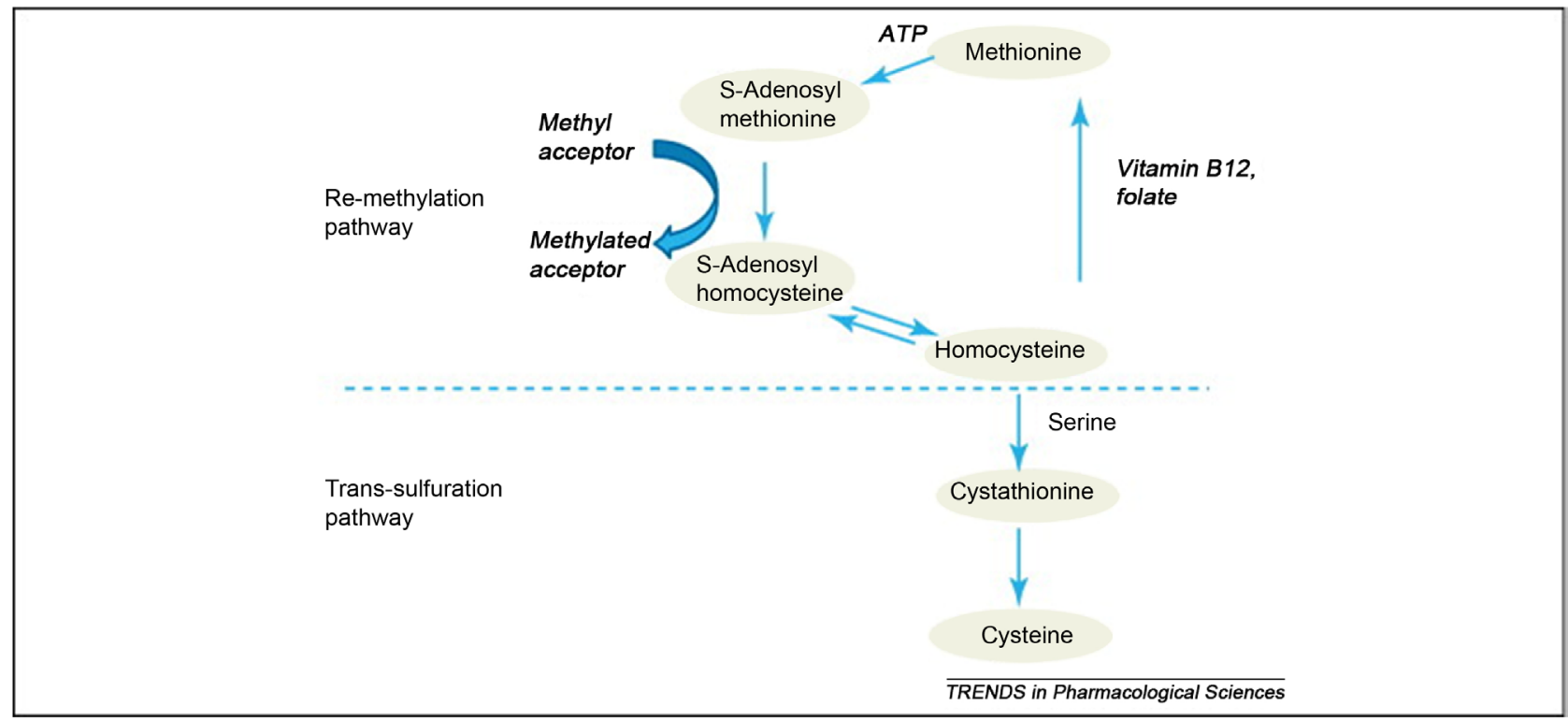

Figure 1. Homocysteine metabolism, ref. [11]. 
pathways are interrupted by any impaired function either by insufficient transsulfuration through CBS mutation or deficiency of vitamin B6 or secondly by remethylation blockage, can lead to abnormal accumulation of plasma Hcy. In the latter case, the accumulation of homocysteine could be due to deficiency of folate or vitamin B12, as well as MTHFR [12]. A condition that emerges from disrupted homocysteine metabolism is hyperhomocysteinemia which has been known as the most significant risk factor for cardiovascular disease and has been confirmed by recently conducted meta-analysis study by Homocysteine Studies Collaboration [13]. Deficiencies in cystathionine beta synthase, methylenetetrahydrofolate reductase or enzymes involving methyl-B12 synthesis, as a result of a rare genetic defect, lead to severe hyperhomocysteinemia. In fasting status, due to mild impairment in the methylation mechanism (i.e. folate or B12 deficiencies or MTHFR thermolability), occurs mild hyperhomocysteinemia [12]. Homocysteine play a role as a mediator for endothelial damage and dysfunction [14] that subsequently impairs endothelial vasoreactivity and decrease endothelium thromboresistance. Hence, hyperhomocysteinemia associated with increased risk of atherosclerosis, thromoboembolic diseases and hyperinsulinemia is verified which is directly proportionate to increased risk of cardiovascular disorders with a strong correlation to insulin resistance. Hyperhomocysteinemia also aggravates the incidence of late pregnancy complications, such as preeclampsia, abruption placentae, preterm birth and intrauterine fetal death [15]. Hyperhomocysteinemia is also one of the major factors that leads to early miscarriages by impairing by interfering endometrial blood flow and vascular integrity [16] and also described as the sole variable resulting in recurrent pregnancy loss [17].

According to numerous clinical studies, PCOS in women is associated with existence of endothelial and platelet dysfunction, minimal chronic inflammation, increased coronary artery calcification and carotid intima-media thickness in PCOS women [18]. PCOS women are highly susceptible to both cardiovascular risk factors, such as, obesity dyslipidemia, hypertension and type-2 diabetes mellitus, and mood disorders, such as depression and anxiety [2].

\section{Homocysteine Status and Association with Other Biochemical Properties}

There are numbers of studies conducted and have confirmed the fact that the plasma Hcy level is significantly raised in women with PCOS. However, few studies fail to affirm obvious changes in the plasma homocysteine level (Table 1). A case-control study conducted in the year 2016 showed that the serum homocysteine levels were significantly high in PCOS women. According to the study, obese women had a higher concentration of plasma Hcy $(13.19 \pm 5.42 \mu \mathrm{mol} / \mathrm{L})$ than non-obese women $(9.38 \pm 2.99 \mu \mathrm{mol} / \mathrm{L})$ with $\mathrm{p}$-value $<0.02$, regardless the participants suffer from PCOS or not [19]. Similarly, a prospective study among 339 women, 84 women had hyperhomocysteinemia with cut off value $>12.4$ $\mu \mathrm{mol} / \mathrm{L}$ and the factor associated to increase the plasma Hcy level was known to be elevated serum total testosterone [20]. The study also reported that 
Table 1. Homocysteine level in PCOS women.

\begin{tabular}{cc}
\hline Increased Hcy level & No significant changes in Hcy level \\
\hline Mahtab Moti et al. 2015 [37] (Iran), $\mathrm{n}=30, \mathrm{p}<0.001$ & Sills et al.,2001 [45] (USA), $\mathrm{n}=36, \mathrm{p}<\mathrm{NS}$ \\
Sachan Rekha et al. 2014 [23] (India), $\mathrm{n}=50, \mathrm{p}<0.001$ & Morgante et al., 2002 [46] (Italy), $\mathrm{n}=20, \mathrm{p}<\mathrm{NS}$ \\
Murat Yilmaz et al. 2005 [40] (Turkey), $\mathrm{n}=50, \mathrm{p}<0.005$ & Orio et al., 2003 [47] (Italy), $\mathrm{n}=70, \mathrm{p}<\mathrm{NS}$ \\
TayebeHemati et al. 2011 [25] (Iran), $\mathrm{n}=64, \mathrm{p}<0.001$ & Mancini et al., 2009 [48] (Italy), $\mathrm{n}=20, \mathrm{p}<\mathrm{NS}$ \\
Morey Schacter et al. 2003 [26] (Israel), $\mathrm{n}=155, \mathrm{p}<0.0001$ & Arikan et al., 2010 [49] (Turkey), $\mathrm{n}=31, \mathrm{p}<\mathrm{NS}$ \\
Priyanka Maleedhu et al. 2014 [41] (India), $\mathrm{n}=142, \mathrm{p}<<0.0001$ & Moini et al., 2011 [50] (Iran), $\mathrm{n}=123, \mathrm{p}<0.157$ \\
Ali I. Gareeb et al. 2016 [19] (Iraq), $\mathrm{n}=101, \mathrm{p}<0.002$ & \\
Mohamadin et al., 2010 [42] (Saudi Arabia), $\mathrm{n}=50, \mathrm{p}<0.001$ & \\
Karaer et al., 2010 [43] (Turkey), $\mathrm{n}=31, \mathrm{p}=0.04$ & \\
Pamuk et al., 2010 [44] (Turkey), $\mathrm{n}=35, \mathrm{p}=0.02$ & \\
Rajagopal et al., 2011 [38] (India), $\mathrm{n}=25$, & \\
Kilic-Okman et al., 2004 [27] (Turkey), $\mathrm{n}=29, \mathrm{p}=0.001$ &
\end{tabular}

hyperhomocysteinemia was identified with biochemical hyperandrogenism but not with clinical hyperandrogenism i.e., hirsutism. Previously, Carmina et al. found significant rise in plasma Hcy level in classic hyperandrogenism with chronic anovulatory PCOS women [21]. A case control study conducted in infertile women found significantly higher level of follicular fluid Hcy in PCOS women that may affect pregnancy outcome undergoing assisted reproduction suggesting of poor oocyte and embryo quality and decreased fertilization rate [22]. The elevated follicular fluid Hcy was not related to parameters such as $\mathrm{E}_{2}$ and glucose level, BMI and age.

Recent research by Sachan Rekha et al. have reported significant higher serum Hcy level in PCOS women, remarkably increased in both obese and non-obese PCOS women and it was best correlated with HOMA-IR out of three indices used for IR [23]. Likewise, other few studies supports that the raised plasma Hcy is correlated with insulin resistance [24]-[34]. Insulin and homocysteine is known to influence each other. A case-control study in adolescent have demonstrated significant increase in serum Hcy level with no difference noted between obese and non-obese PCOS and was positively correlated with IR. Correspondingly, Sedigheh Esmaeilzadeh et al. and Rosolova et al. unexpectedly found inverse relationship between Hcy levels and IR [35] [36]. On contrary, few authors have demonstrated that serum Hcy level is not associated with IR [19] [20] [37] [38] [39].

\section{Influence on Hcy Level Post PCOS Therapy}

Insulin and Hcy have the ability to induce each other by inhibiting hepatic CBS [23] that results in hyperhomocysteinemia leading to compensatory hyperinsulinemia by inducing insulin resistance. This may impair activity of the MTHFR or CBS enzymes, leading to abnormal deposition of homocysteine in plasma [24] [51] [52]. This explains that insulin resistance may be the most important mark- 
er of metabolic disease in PCOS women [53]. Hence, metformin has always been the mainstay treatment for PCOS women with insulin resistance. With administration of metformin, some study has shown beneficial decrease in plasma Hcy level [8] [54]. Nonetheless, it is also studied that metformin monotherapy is unsatisfactory [55]. The study conducted by Vrbrikova et al. revealed that the treatment with metformin only may increase the plasma Hcy level [56]. Administration with rosiglitazone and metformin seem to decrease elevated oxidative stress compared to metformin treatment but no significant changes were observed in plasma Hcy [40]. Kilicdag et al. also reported the same result [57]. This statement can be explained by folate depletion and malabsorption of vitamin B12 [58] [59] that disturbs Hcy metabolism, thus, supplementation with folate can be preventative [57] [60]. Moreover, treatment with metformin and cyclic medroxyprogesterone acetate (MPA) also tend to increase Hcy level [55]. Stefano Palombo et al. reported that treatment with metformin can slightly reduce the Hcy level in PCOS women, but supplementation with folate has shown to increase the beneficial effect [60]. Hence, folate supplementation is the first therapeutic measure advised in obese PCOS patients that prevents rise in Hcy level during weight loss. A prospective randomized clinical study in 2010, in both obese and non-obese PCOS women, observed dramatic decrease in plasma Hcy level when treated with metformin. However, the study in the both group when treated with oral contraceptives increased the plasma Hcy level and other biochemical parameters that increased the metabolic risk [61].

Statins have also been administered and seems to deplete serum Hcy levels in PCOS [48] [62]. In a prospective cohort study, the combination of ethinyl estradiol/drospirenone (EE-DRSP) and spironolactone treatment were given to lean and glucose tolerant patients with PCOS for 6 months, improved androgen excess but the combination increased Hcy level and CRP level [63]. Similarly, oral contraceptives containing $0.03 \mathrm{mg}$ ethinyl estradiol and $0.15 \mathrm{mg}$ desogestrel for 6 months had significantly decreased Hcy level in non-obese normoandrogenic PCOS patients [61]. Furthermore, oral contraceptives containing $35 \mu \mathrm{g}$ ethinyl estradiol and $2 \mathrm{mg}$ cyproterone acetate had resulted in rapid decrease in Hcy level in non-smoking PCOS women [64] [65] [66], whereas Hcy level remains high in the smokers. It has also been studied that Hcy levels decreased after regular exercises for 6 months [67] and also have shown to decrease 3 months after ovarian surgery [68]. The treatment of above mentioned studies are summarized in the tables (Tables 2-4).

\section{Conclusion}

PCOS, also known as Stein-Leventhal syndrome, is not only a gynecological disorder, but a sequence of endocrine disorder amongst women in reproductive age, metabolic imbalance such as insulin resistance and dyslipidemia, associated chemical and biochemical hyperandrogenemia that optimally results in psychological disorder. PCOS has been the topic of debate since many decades with greater evidence of Hcy metabolism disturbances. The raised plasma homocysteine 
Table 2. Treatment with metformin monotherapy.

\begin{tabular}{|c|c|c|c|c|c|}
\hline STUDY & DOSE & DURATION & BEFORE TREATMENT & AFTER TREATMENT & P VALUE \\
\hline Riahinejad(2015) & $850 \mathrm{mg}$ OD & 3 months & $9.11 \pm 2.7$ & $8.55 \pm 2.49$ & 0.035 \\
\hline Sahin (2007) & $2550 \mathrm{mg}$ OD & 6 months & $12.8 \pm 5.2$ & $12.3 \pm 5.6$ & NS \\
\hline Vrbivoka (2002) & $\begin{array}{c}500 \mathrm{mg} \text { OD initially } \\
\text { and increased to } \\
1000 \mathrm{mg} \mathrm{OD}\end{array}$ & 1 week & $10.1 \pm 2.6$ & $13.4 \pm 5.1$ & $<0.05$ \\
\hline Haydardedeoglu (2009) & $850 \mathrm{mg} \mathrm{BD}$ & 6 months & $8.74 \pm 1.9$ & $10.97 \pm 3.31$ & 0.002 \\
\hline Yilmaz (2005) & $850 \mathrm{mg} \mathrm{BD}$ & 3 months & $13.52 \pm 5.98$ & $13.46 \pm 6.01$ & NS \\
\hline Kilicdag (2005) & $850 \mathrm{mg} \mathrm{BD}$ & 3 months & $8.93 \pm 0.49$ & $11.26 \pm 0.86$ & 0.002 \\
\hline Palombo (2010) & $1750 \mathrm{mg}$ OD & 3 months & $11.1 \pm 4.4$ & $13.9 \pm 3.8$ & $<0.05$ \\
\hline \multirow[t]{3}{*}{ Kilic S (2010) } & $850 \mathrm{mg} \mathrm{BD}$ & 6 months & $8.99 \pm 2.24$ & $6.78 \pm 2.15$ & $<0.001$ \\
\hline & & 6 months (obese) & $8.35 \pm 2.22$ & $6.64 \pm 3.34$ & 0.002 \\
\hline & & months (non-obese) & & & \\
\hline
\end{tabular}

Table 3. Treatment with metformin and other drugs.

\begin{tabular}{cccccc}
\hline STUDY & \multirow{2}{*}{ DRUGS } & DOSE AND DURATION & $\begin{array}{c}\text { BEFORE } \\
\text { TREATMENT }\end{array}$ & $\begin{array}{c}\text { AFTER } \\
\text { TREATMENT }\end{array}$ & P VALUE \\
\hline Haydardedeoglu (2009) & Metformin + MPA & $850 \mathrm{mg}+5 \mathrm{mg} * 3$ months & $12.82 \pm 6.89$ & $14.66 \pm 7.11$ & 0.111 \\
Palombo (2010) & Metformin + folate & $1750 \mathrm{mg}+400 \mu \mathrm{g} * 6 \mathrm{months}$ & $10.5 \pm 3.9$ & $9.7 \pm 4.2$ & $<0.05$ \\
\hline
\end{tabular}

Table 4. Treatment with other drugs.

\begin{tabular}{|c|c|c|c|c|c|}
\hline STUDY & DRUGS & $\begin{array}{l}\text { DOSE AND } \\
\text { DURATION }\end{array}$ & $\begin{array}{c}\text { BEFORE } \\
\text { TREATMENT }\end{array}$ & AFTER TREATMENT & P VALUE \\
\hline Cemil kaya (2009) & Atorvastatin & $20 \mathrm{mg} \mathrm{OD} * 3$ months & $14.3 \pm 2.9$ & $10.6 \pm 1.7$ & $<0.01$ \\
\hline Harmanci (2013) & Simvastatin & $20 \mathrm{mg} \mathrm{OD} \star 3$ months & $13.6 \pm 2.1$ & $11.1 \pm 1.9$ & $<0.05$ \\
\hline Yilmaz (2005) & EE-DSRP + spironolactone & $\begin{array}{c}3 \mathrm{mg} / 30 \mu \mathrm{g}+100 \mathrm{mg} \\
\mathrm{OD}{ }^{*} 6 \text { months }\end{array}$ & $13.1 \pm 5.2$ & $17.6 \pm 5.3$ & $<0.05$ \\
\hline Cagnacci (2006) & Rosiglitazone & $4 \mathrm{mg} \mathrm{OD} * 3$ months & $13.94 \pm 6.72$ & $13.2 \pm 5.88$ & NS \\
\hline \multirow[t]{3}{*}{ Gul OB (2008) } & EE/DSG & $\begin{array}{c}40 / 30 \mu \mathrm{g}+25 / 125 \mathrm{mg} \\
\mathrm{OD}^{\star} 6 \text { months }\end{array}$ & $9.54 \pm 0.7$ & $9.8 \pm 0.6$ & NS \\
\hline & $\mathrm{EE} / \mathrm{CPA}$ & $\begin{array}{c}35 \mu \mathrm{g}+2 \mathrm{mg} \mathrm{OD}{ }^{*} 6 \\
\text { months }\end{array}$ & $9.8 \pm 1.9$ & $7.9 \pm 0.9$ & $<0.05$ \\
\hline & $\mathrm{EE} / \mathrm{CPA}$ & $\begin{array}{c}35 \mu \mathrm{g}+2 \mathrm{mg} \mathrm{OD} * 3 \\
\text { months }\end{array}$ & $55.97 \pm 16.04$ & $54.03 \pm 16.15$ & 0.001 \\
\hline
\end{tabular}

have been extensively approved as an absolute risk factor for cardiovascular disease. Basal Hcy level is gradually increased after menopause that explains the cardiovascular risk burden and can be prevented in some extents by hormone replacement therapy [69]. There is still need of further study to gain clear knowledge about the role of homocysteine in PCOS and to clarify the relationship between insulin resistance, androgen levels and other biochemical parameters, thus, enlightening the better treatment options and avert women from short and long term risk factors such as cardiovascular disease, type 2 diabetes mellitus, 
infertility, recurrent miscarriages and psychological disorder. Once obtained the desired goal, women with PCOS can thus lead a better quality of life.

\section{References}

[1] Huijgen, N.A., Laven, J.S., Labee, C.T., Louwers, Y.V., Willemsen, S.P. and Steegers-Theunissen, R.P. (2015) Are Dieting and Dietary Inadequacy a Second Hit in the Association with Polycystic Ovary Syndrome Severity? PloS ONE, 10, Article ID: e0142772. https://doi.org/10.1371/journal.pone.0142772

[2] Palomba, S., Santagni, S., Falbo, A. and La Sala, G.B. (2015) Complications and Challenges Associated with Polycystic Ovary Syndrome: Current Perspectives. International Journal of Women's Health, 7, 745-763. https://doi.org/10.2147/IJWH.S70314

[3] March, W.A., Moore, V.M., Willson, K.J., Phillips, D.I., Norman, R.J. and Davies, M.J. (2010) The Prevalence of Polycystic Ovary Syndrome in a Community Sample Assessed under Contrasting Diagnostic Criteria. Human Reproduction, 25, 544-551. https://doi.org/10.1093/humrep/dep399

[4] Kamangar, F., Okhovat, J.P., Schmidt, T., Beshay, A., Pasch, L., Cedars, M.I., et al. (2015) Polycystic Ovary Syndrome: Special Diagnostic and Therapeutic Considerations for Children. Pediatric Dermatology, 32, 571-578. https://doi.org/10.1111/pde.12566

[5] Baldani, D.P., Skrgatic, L. and Ougouag, R. (2015) Polycystic Ovary Syndrome: Important Underrecognised Cardiometabolic Risk Factor in Reproductive-Age Women. International Journal of Endocrinology, 2015, 17. https://doi.org/10.1155/2015/786362

[6] Teede, H., Deeks, A. and Moran, L. (2010) Polycystic Ovary Syndrome: A Complex Condition with Psychological, Reproductive and Metabolic Manifestations That Impacts on Health across the Lifespan. BMC Medicine, 8, 41. https://doi.org/10.1186/1741-7015-8-41

[7] Legro, R.S., Arslanian, S.A., Ehrmann, D.A., Hoeger, K.M., Murad, M.H., Pasquali, R., et al. (2013) Diagnosis and Treatment of Polycystic Ovary Syndrome: An Endocrine Society Clinical Practice Guideline. The Journal of Clinical Endocrinology \& Metabolism, 98, 4565-4592. https://doi.org/10.1210/jc.2013-2350

[8] Riahinejad, S., Mirdamadi, A. and Alizadeh, E. (2015) Effects of Metformin Treatment on Homocysteine Levels and Metabolic Parameters of Women with Polycystic Ovary Syndrome. Journal of Family \& Reproductive Health, 9, 172.

[9] Barber, T.M. and Franks, S. (2013) Genetics of Polycystic Ovary Syndrome. In: Polycystic Ovary Syndrome, Karger Publishers, Basel, 28-39.

[10] El Hayek, S., Bitar, L., Hamdar, L.H., Mirza, F.G. and Daoud, G. (2016) Poly Cystic Ovarian Syndrome: An Updated Overview. Frontiers in Physiology, 7, 124. https://doi.org/10.3389/fphys.2016.00124

[11] Zhuo, J.-M., Wang, H. and Praticò, D. (2011) Is Hyperhomocysteinemia an Alzheimer's Disease (AD) Risk Factor, an AD Marker, or Neither? Trends in Pharmacological Sciences, 32, 562-571. https://doi.org/10.1016/j.tips.2011.05.003

[12] Selhub, J. (1999) Homocysteine Metabolism. Annual Review of Nutrition, 19, 217-246. https://doi.org/10.1146/annurev.nutr.19.1.217

[13] Collaboration, H.S. (2002) Homocysteine and Risk of Ischemic Heart Disease and Stroke: A Meta-Analysis. Jama, 288, 2015-2022. https://doi.org/10.1001/jama.288.16.2015 
[14] Van Guldener, C. and Stehouwer, C. (2000) Hyperhomocysteinemia, Vascular Pathology, and Endothelial Dysfunction. Seminars in Thrombosis and Hemostasis. Thieme Medical Publishers, Inc., New York, 281-290. https://doi.org/10.1055/s-2000-8472

[15] Forges, T., Monnier-Barbarino, P., Alberto, J., Gueant-Rodriguez, R., Daval, J. and Gueant, J. (2007) Impact of Folate and Homocysteine Metabolism on Human Reproductive Health. Human Reproduction Update, 13, 225-238. https://doi.org/10.1093/humupd/dml063

[16] Del Bianco, A., Maruotti, G., Fulgieri, A., Celeste, T., Lombardi, L., Amato, N., et al. (2004) Recurrent Spontaneous Miscarriages and Hyperhomocysteinemia. Minerva Ginecologica, 56, 379-383.

[17] Chakraborty, P., Goswami, S.K., Rajani, S., Sharma, S., Kabir, S.N., Chakravarty, B., et al. (2013) Recurrent Pregnancy Loss in Polycystic Ovary Syndrome: Role of Hyperhomocysteinemia and Insulin Resistance. PLoS ONE, 8, e64446. https://doi.org/10.1371/journal.pone.0064446

[18] Rotterdam, E. and Group A-SPCW (2004) Revised 2003 Consensus on Diagnostic Criteria and Long-Term Health Risks Related to Polycystic Ovary Syndrome (PCOS). Human Reproduction (Oxford, England), 19, 41-47. https://doi.org/10.1093/humrep/deh098

[19] Al-Gareeb, A.I., Al-Amieer, W.S.A., Alkuraishy, H.M. and Al-Mayahi, T.J. (2016) Effect of Body Weight on Serum Homocysteine Level in Patients with Polycystic Ovarian Syndrome: A Case Control Study. International Journal of Reproductive BioMedicine, 14, 81-88.

[20] Lin, Y.H., Huang, S.Y., Hsu, M.I., Chang, Y.C., Cheng, C.Y., Hsu, C.S., et al. (2013) Hyperhomocysteinaemia Is Associated with Biochemical Hyperandrogenaemia in Women with Reproductive Age. European Journal of Obstetrics, Gynecology, and Reproductive Biology, 171, 314-318. https://doi.org/10.1016/j.ejogrb.2013.09.041

[21] Carmina, E., Chu, M.C., Longo, R.A., Rini, G.B. and Lobo, R.A. (2005) Phenotypic Variation in Hyperandrogenic Women Influences the Findings of Abnormal Metabolic and Cardiovascular Risk Parameters. The Journal of Clinical Endocrinology and Metabolism, 90, 2545-2549. https://doi.org/10.1210/jc.2004-2279

[22] Eskandari, Z., Sadrkhanlou, R.-A., Nejati, V. and Tizro, G. (2016) PCOS Women Show Significantly Higher Homocysteine Level, Independent to Glucose and E2 Level. International Journal of Reproductive BioMedicine, 14, 495-500.

[23] Rekha, S., Patel, M., Pooja, G., Amita, D., Pushplata, S. and Natu, S. (2013) Correlation between Elevated Homocysteine Levels and Insulin Resistance in Infertile Women with or without Polycystic Ovary Syndrome in North Indian Population. International Journal of Medicine and Medical Sciences, 5, 116-123.

[24] Altug Sen, T., Koken, R., Narci, A. and Yilmazer, M. (2011) Homocysteine and Ghrelin Link with Polcystic Ovary Syndrome in Relation to Obesity. Journal of Pediatric and Adolescent Gynecology, 24, 211-217. https://doi.org/10.1016/j.jpag.2011.02.007

[25] Hemati, T., Moghadami-Tabrizi, N., Davari-Tanha, F., Salmanian, B. and Javadian, P. (2011) High Plasma Homocysteine and Insulin Resistance in Patients with Polycystic Ovarian Syndrome. Iranian Journal of Reproductive Medicine, 9, 223-228.

[26] Schachter, M., Raziel, A., Friedler, S., Strassburger, D., Bern, O. and Ron-El, R. (2003) Insulin Resistance in Patients with Polycystic Ovary Syndrome Is Associated with Elevated Plasma Homocysteine. Human Reproduction, 18, 721-727. https://doi.org/10.1093/humrep/deg190 
[27] Kilic-Okman, T., Guldiken, S. and Kucuk, M. (2004) Relationship between Homocysteine and Insulin Resistance in Women with Polycystic Ovary Syndrome. Endocrine Journal, 51, 505-508. https://doi.org/10.1507/endocrj.51.505

[28] Atamer, A., Demir, B., Bayhan, G., Atamer, Y., Ilhan, N. and Akkuş, Z. (2008) Serum Levels of Leptin and Homocysteine in Women with Polycystic Ovary Syndrome and Its Relationship to Endocrine, Clinical and Metabolic Parameters. Journal of International Medical Research, 36, 96-105.

https://doi.org/10.1177/147323000803600113

[29] Bayraktar, F., Dereli, D., Özgen, A.G. and Yilmaz, C. (2004) Plasma Homocysteine Levels in Polycystic Ovary Syndrome and Congenital Adrenal Hyperplasia. Endocrine Journal, 51, 601-608. https://doi.org/10.1507/endocrj.51.601

[30] Gupta, M.M., Chari, S., Chandankhede, M. and Ghike, S. (2013) Insulin Resistance and Homocysteine Levels in Patients with Polycystic Ovarian Syndrome. Journal of South Asian Federation of Obstetrics and Gynaecology, 5, 49-51.

https://doi.org/10.1111/j.1447-0756.1977.tb00351.x

[31] Badawy, A., State, O., El Gawad, S. and El Aziz, O.A. (2007) Plasma Homocysteine and Polycystic Ovary Syndrome: The Missed Link. European Journal of Obstetrics, Gynecology, and Reproductive Biology, 131, 68-72.

https://doi.org/10.1016/j.ejogrb.2006.10.015

[32] Oktem, M., Ozcimen, E.E., Uckuyu, A., Esinler, I., Pamuk, B., Bayraktar, N., et al. (2009) Polycystic Ovary Syndrome Is Associated with Elevated Plasma Soluble CD40 Ligand, a Marker of Coronary Artery Disease. Fertility and Sterility, 91, 2545-2550. https://doi.org/10.1016/j.fertnstert.2008.03.039

[33] Salehpour, S., Ozra Manzor-al-ajdad, M., Elham Neisani Samani, M. and Abadi, A. (2011) Evaluation of Homocysteine Levels in Patients with Polycystic Ovarian Syndrome. International Journal of Fertility \& Sterility, 4, 168-171.

[34] Topcu, S., Caliskan, M., Ozcimen, E.E., Tok, D., Uckuyu, A., Erdogan, D., et al. (2006) Do Young Women with Polycystic Ovary Syndrome Show Early Evidence of Preclinical Coronary Artery Disease? Human Reproduction, 21, 930-935. https://doi.org/10.1093/humrep/dei431

[35] Esmaeilzadeh, S., Tahmasbpour, E. and Gholinezhad-Chari, M. (2017) Hyperhomocysteinemia, Insulin Resistance and Body Mass Index in Iranian Young Women with Polycystic Ovary Syndrome. Middle East Fertility Society Journal, 22, 149-155. https://doi.org/10.1016/j.mefs.2017.01.007

[36] Jacobsen, D. (2002) Unexpected Inverse Relationship between Insulin Resistance and Serum Homocysteine in Healthy Subjects. Physiological Research, 51, 93-98.

[37] Moti, M., Amini, L., Ardakani, S.S.M., Kamalzadeh, S. and Masoomikarimi, M. (2015) Oxidative Stress and Anti-Oxidant Defense System in Iranian Women with Polycystic Ovary Syndrome. Iranian Journal of Reproductive Medicine, 13, 373-378.

[38] Rajagopal, G., Reddy, A.P., Venkata Harinarayan, C., Suresh, V., Bitla, A., Pvlnr, S., et al. (2012) Effect of Lifestyle Modification and Metformin Therapy on Emerging Cardiovascular Risk Factors in Overweight Indian Women with Polycystic Ovary Syndrome. Metabolic Syndrome and Related Disorders, 10, 273-279.

https://doi.org/10.1089/met.2011.0127

[39] Caglar, G.S., Oztas, E., Karadag, D., Pabuccu, R. and Demirtas, S. (2011) Ischemia-Modified Albumin and Cardiovascular Risk Markers in Polycystic Ovary Syndrome with or without Insulin Resistance. Fertility and Sterility, 95, 310-313. https://doi.org/10.1016/j.fertnstert.2010.06.092

[40] Yilmaz, M., Bukan, N., Ayvaz, G., Karakoc, A., Toruner, F., Cakir, N., et al. (2005) 
The Effects of Rosiglitazone and Metformin on Oxidative Stress and Homocysteine Levels in Lean Patients with Polycystic Ovary Syndrome. Human Reproduction, 20, 3333-3340. https://doi.org/10.1093/humrep/dei258

[41] Maleedhu, P., Kodumuri, P.K. and Devi, D.V. (2014) Status of Homocysteine in Polycystic Ovary Syndrome (PCOS). Journal of Clinical and Diagnostic Research, 8, 31-33.

[42] Mohamadin, A.M., Habib, F.A. and Al-Saggaf, A.A. (2010) Cardiovascular Disease Markers in Women with Polycystic Ovary Syndrome with Emphasis on Asymmetric Dimethylarginine and Homocysteine. Annals of Saudi Medicine, 30, 278-283. https://doi.org/10.4103/0256-4947.65255

[43] Karaer, A., Cavkaytar, S., Mert, I., Buyukkagnici, U. and Batioglu, S. (2010) Cardiovascular Risk Factors in Polycystic Ovary Syndrome. Journal of Obstetrics and Gynaecology, 30, 387-392. https://doi.org/10.3109/01443611003763408

[44] Pamuk, B.O., Torun, A.N., Kulaksizoglu, M., Ertugrul, D., Ciftci, O., Kulaksizoglu, S., et al. (2010) Asymmetric Dimethylarginine Levels and Carotid Intima-Media Thickness in Obese Patients with Polycystic Ovary Syndrome and Their Relationship to Metabolic Parameters. Fertility and Sterility, 93, 1227-1233. https://doi.org/10.1016/j.fertnstert.2008.10.073

[45] Sills, E.S., Genton, M.G., Perloe, M., Schattman, G.L., Bralley, J.A. and Tucker, M.J. (2001) Plasma Homocysteine, Fasting Insulin, and Androgen Patterns among Women with Polycystic Ovaries and Infertility. Journal of Obstetrics and Gynaecology Research, 27, 163-168. https://doi.org/10.1111/j.1447-0756.2001.tb01241.x

[46] Morgante, G., la Marca, A., Setacci, F., Setacci, C., Petraglia, F. and De Leo, V. (2002) The Cardiovascular Risk Factor Homocysteine Is Not Elevated in Young Women with Hyperandrogenism or Hypoestrogenism. Gynecologic and Obstetric Investigation, 53, 200-203. https://doi.org/10.1159/000064561

[47] Orio, F., Palomba, S., Di Biase, S., Colao, A., Tauchmanova, L., Savastano, S., et al. (2003) Homocysteine Levels and C677T Polymorphism of Methylenetetrahydrofolate Reductase in Women with Polycystic Ovary Syndrome. The Journal of Clinical Endocrinology and Metabolism, 88, 673-679.

https://doi.org/10.1210/jc.2002-021142

[48] Mancini, F., Cianciosi, A., Reggiani, G.M., Facchinetti, F., Battaglia, C. and de Aloysio, D. (2009) Endothelial Function and Its Relationship to Leptin, Homocysteine, and Insulin Resistance in Lean and Overweight Eumenorrheic Women and PCOS Patients: A Pilot Study. Fertility and Sterility, 91, 2537-2544. https://doi.org/10.1016/j.fertnstert.2008.03.023

[49] Arikan, Ş., Bahceci, M., Tuzcu, A., Kale, E. and Gökalp, D. (2010) Serum Resistin and Adiponectin Levels in Young Non-Obese Women with Polycystic Ovary Syndrome. Gynecological Endocrinology, 26, 161-166.

https://doi.org/10.3109/09513590903247816

[50] Moini, A., Sarrafion, F., Ziaei, S., Faghihzadeh, S. and Arabipoor, A. (2011) A Possible Role for Familial Thrombophilia in Women with Polycystic Ovarian Syndrome. Gynecological Endocrinology, 27, 80-85. https://doi.org/10.3109/09513590.2010.488768

[51] Welch, G.N. and Loscalzo, J. (1998) Homocysteine and Atherothrombosis. New England Journal of Medicine, 338, 1042-1050. https://doi.org/10.1056/NEJM199804093381507

[52] Dicker-brown, A., Fonseca, V.A., Fink, L.M. and Kern, P.A. (1999) The Effect of Glucose and Insulin on the Activity of Enzymes in Homocysteine Metabolism. Diabetes, 48, SA135. 
[53] Traub, M.L. (2011) Assessing and Treating Insulin Resistance in Women with Polycystic Ovarian Syndrome. World Journal of Diabetes, 2, 33-40. https://doi.org/10.4239/wjd.v2.i3.33

[54] Sahin, Y., Unluhizarci, K., Yilmazsoy, A., Yikilmaz, A., Aygen, E. and Kelestimur, F. (2007) The Effects of Metformin on Metabolic and Cardiovascular Risk Factors in Nonobese Women with Polycystic Ovary Syndrome. Clinical Endocrinology, 67, 904-908. https://doi.org/10.1111/j.1365-2265.2007.02985.x

[55] Haydardedeoglu, B., Simsek, E., Kilicdag, E.B. and Bagis, T. (2009) Metabolic and Endocrine Effects of Metformin and Metformin plus Cyclic Medroxyprogesterone Acetate in Women with Polycystic Ovary Syndrome. International Journal of Gynaecology and Obstetrics. The Official Organ of the International Federation of Gynaecology and Obstetrics, 105, 32-35. https://doi.org/10.1016/j.ijgo.2008.11.039

[56] Vrbikova, J., Bičíková, M., Tallova, J., Hill, M. and Starka, L. (2002) Homocysteine and Steroids Levels in Metformin Treated Women with Polycystic Ovary Syndrome. Experimental and Clinical Endocrinology \& Diabetes, 110, 74-76. https://doi.org/10.1055/s-2002-23489

[57] Kilicdag, E.B., Bagis, T., Zeyneloglu, H.B., Tarim, E., Aslan, E., Haydardedeoglu, B., et al. (2005) Homocysteine Levels in Women with Polycystic Ovary Syndrome Treated with Metformin versus Rosiglitazone: A Randomized Study. Human Reproduction, 20, 894-899. https://doi.org/10.1093/humrep/deh700

[58] Obeid, R. (2014) Metformin Causing Vitamin B12 Deficiency: A Guilty Verdict without Sufficient Evidence. Diabetes Care, 37, e22-e32. https://doi.org/10.2337/dc13-2278

[59] Xu, L., Huang, Z., He, X., Wan, X., Fang, D. and Li, Y. (2013) Adverse Effect of Metformin Therapy on Serum Vitamin B12 and Folate: Short-Term Treatment Causes Disadvantages? Medical Hypotheses, 81, 149-151. https://doi.org/10.1016/j.mehy.2013.05.025

[60] Palomba, S., Falbo, A., Giallauria, F., Russo, T., Tolino, A., Zullo, F., et al. (2010) Effects of Metformin with or without Supplementation with Folate on Homocysteine Levels and Vascular Endothelium of Women with Polycystic Ovary Syndrome. Diabetes Care, 33, 246-251. https://doi.org/10.2337/dc09-1516

[61] Kilic, S., Yilmaz, N., Zulfikaroglu, E., Erdogan, G., Aydin, M. and Batioglu, S. (2011) Inflammatory-Metabolic Parameters in Obese and Nonobese Normoandrogenemic Polycystic Ovary Syndrome during Metformin and Oral Contraceptive Treatment. Gynecological Endocrinology, 27, 622-629. https://doi.org/10.3109/09513590.2010.530706

[62] Kaya, C., Cengiz, S.D., Berker, B., Demirtas, S., Cesur, M. and Erdogan, G. (2009) Comparative Effects of Atorvastatin and Simvastatin on the Plasma Total Homocysteine Levels in Women with Polycystic Ovary Syndrome: A Prospective Randomized Study. Fertility and Sterility, 92, 635-642. https://doi.org/10.1016/j.fertnstert.2008.06.006

[63] Harmanci, A., Cinar, N., Bayraktar, M. and Yildiz, B.O. (2013) Oral Contraceptive plus Antiandrogen Therapy and Cardiometabolic Risk in Polycystic Ovary Syndrome. Clinical Endocrinology, 78, 120-125. https://doi.org/10.1111/j.1365-2265.2012.04466.x

[64] Cagnacci, A., Tirelli, A., Renzi, A., Paoletti, A.M. and Volpe, A. (2006) Effects of Two Different Oral Contraceptives on Homocysteine Metabolism in Women with Polycystic Ovary Syndrome. Contraception, 73, 348-351. https://doi.org/10.1016/j.contraception.2005.09.011 
[65] Gul, O.B., Somunkiran, A., Yucel, O., Demirci, F. and Ozdemir, I. (2008) The Effect of Ethinyl Estradiol-Cyproterone Acetate Treatment on Homocysteine Levels in Women with Polycystic Ovary Syndrome. Archives of Gynecology and Obstetrics, 277, 25-30. https://doi.org/10.1007/s00404-007-0401-x

[66] Luque-Ramírez, M., Mendieta-Azcona, C. and del Rey Sanchez, J. (2009) Effects of an Antiandrogenic OCP's Compared with Metformin on Blood Coagulation Tests and Endothelial Function in Women with the PCOS, Influence of Obesity and Smoking. European Journal of Endocrinology, 160, 469-480.

https://doi.org/10.1530/EJE-08-0725

[67] Randeva, H.S., Lewandowski, K.C., Drzewoski, J.Z., Brooke-Wavell, K., O'callaghan, C., Czupryniak, L., et al. (2002) Exercise Decreases Plasma Total Homocysteine in Overweight Young Women with Polycystic Ovary Syndrome. The Journal of Clinical Endocrinology \& Metabolism, 87, 4496-4501.

https://doi.org/10.1210/jc.2001-012056

[68] Kucuk, M. and Kilic-Okman, T. (2005) Hormone Profiles and Clinical Outcome after Laparoscopic Ovarian Drilling in Women with Polycystic Ovary Syndrome. Medical Science Monitor, 11, CR29-CR34.

[69] Van Baal, W.M., Smolders, R.G., Van der Mooren, M.J., Teerlink, T. and Kenemans, P. (1999) Hormone Replacement Therapy and Plasma Homocysteine Levels. Obstetrics \& Gynecology, 94, 485-491.

https://doi.org/10.1097/00006250-199910000-00001

\author{
Abbreviations \\ PCOS: Polycystic Ovary Syndrome \\ NIH: National Institute Health \\ Hcy: Homocysteine \\ HOMA-IR: Homeostasis Model Assessment-Insulin resistance \\ SAM: S-adenosylmethionine \\ MTHFR: Methylenetetrahydrofolate reductase \\ CBS: Cystathionine Beta Synthase \\ $\mathrm{E}_{2}$ : Estradiol \\ BMI: Body mass index \\ MPA: Medroxyprogesterone acetate \\ EE: Ethinyl estradiol \\ DRSP: Ethinyl estradiol-Drospirenone \\ CRP: c-reactive protein \\ CPA: Crypterone acetate \\ DSG: Desogestrel
}

